\title{
Applications of DHM in Agricultural Engineering: A Review
}

\author{
Thaneswer Patel ${ }^{1 a}$, Sanjog J. ${ }^{2 b}$, Anirban Chowdhury ${ }^{2 c}$ \\ and Sougata Karmakar ${ }^{2 \mathrm{~d}}$ \\ ${ }^{1}$ Dept. of Agricultural Engineering, North Eastern Regional Institute of Science and Technology \\ (NERIST), Arunachal Pradesh, India. \\ ${ }^{2}$ Department of Design, Indian Institute of Technology (IIT) Guwahati, Assam, India. \\ athaneswer@gmail.com, bjsanjog@yahoo.com, chowdhuryanirban14@gmail.com, \\ dkarmakar.sougata@gmail.com
}

Keywords: digital human modeling, CAD, agriculture, farm machinery, ergonomics, virtual evaluation

\begin{abstract}
Research towards developing user-compatible, ease in use and safe agricultural equipment with proper consideration of human factors using cutting edge technology like Digital Human Modeling (DHM) and simulation is very important in today's scenario. This technology offers new possibilities to integrate ergonomics principles into design process from the very beginning (conceptual phase) to solve complex problems in many engineering disciplines. However, its application is till very limited in agricultural sector. This paper provides overview of up-to-date research in virtual ergonomics evaluation technology (through DHM) and its applications in agriculture. Attempt has also been made to highlight future research direction in many areas of agricultural sectors where DHM might contribute potentially for ergonomic interventions to reduce drudgery and chances of errors and accidents. Authors have also identified reasons behind less adoption of this technology in agricultural sectors and tried to highlight strategies to be followed for wide adoption.
\end{abstract}

\section{Introduction}

Agriculture is still recognized as one of the most hazardous industry, following mining and construction because of the nature of agricultural machines and conditions under which they are operated [1]. On one hand, use of local artisans made primitive tools/equipment are found ineffective/not well suited with user's physical capacity in developing and least developed countries and thus causes physical strain and fatigue which very often not only results in less productivity but also leads to accidents and injuries. On the other hand, rapid mechanization in agriculture in different developed and developing countries is creating challenges like hazardous work environment and increased number of accidents. Therefore, agricultural tools/equipment and workplaces are needed to be designed considering human factor issues using state-of-the-art technologies as described in subsequent sections.

Ergonomics/Human factors in agriculture: Professionals and researchers from diverse fields are in constant attempt for improvement of agricultural hand tools, farm machineries, agricultural vehicles etc. to provide more user friendly facilities. Now-a-days it is well known that incorporation of ergonomics principle in any product/workplace or process design can offer better performance, productivity and at the same time reduction in errors and accidents in any sector [2]. Agricultural sector is not an exception for the same. As incidents of accident and other occupational health hazards are very highly associated with agricultural operations, enough research and development are still needed and fruitful results are to be implemented in a cost-effective manner to ameliorate present situation.

Conventional ergonomics approach in agriculture: Application of ergonomics principles in agriculture has a long history. Traditional ergonomics evaluation process involve full-size physical mock-up, selection of a representative sample of potential users for executing a series of appropriate 
human factors evaluations and it is also time consuming, reactive, incomplete, sporadic, and in many cases difficult, too [3]. Although it is well understood that use of scientific and technological advancements will improve the quality as well as productivity with less time and cost but the use of traditional approach of ergonomic evaluation is still in practice for improvement of existing designs of farm tools and implements [4-9]

Need of virtual ergonomics evaluation techniques in agriculture: Virtual designing and evaluation technology is now widely accepted as a major breakthrough in scientific and technological advancement which leads new possibilities to solve intricate problems, not only in engineering but also in other applied areas including agricultural sector. Need for implementation of virtual ergonomics evaluation technology in agriculture can be perceived by recognizing the problems associated with traditional methods for design, development and ergonomic evaluation. There is no doubt that usage of computer aided technology has brought avant-garde changes in many multidisciplinary scientific fields. Unfortunately, this technology has not got momentum, particularly in agricultural sectors where farming tools and equipment are still evaluated by traditional ergonomic assessment methods. Digital human modeling (DHM) software allows configurations and design changes in the virtual design stage, thus reducing the risk of ergonomics problems in development stages before making the actual prototype. It would go a long way toward bringing the principles of ergonomics and elucidating the scope and benefits of its applications.

\section{Aim and Objectives}

To date, most of the applications of DHM research are associated with sectors like Aviation, Aerospace, Military research and Automobile, while limited information is available on use of the same in agricultural sectors particularly for ergonomic design and evaluation of farm machineries/equipment. Moreover, available information is discrete in nature and there is a strong need of a concrete knowledge base regarding application of DHM in agriculture to strengthen and promote further research in this sector. Thus, the aim of the present review is to highlight existing scenario of DHM applications in agricultural sectors for design and development of cost effective agricultural tools/equipment. Attempt has also been made to find out reasons behind less adoption of these technologies in agricultural sectors and to highlight strategies to be followed for their wide adoption to design and develop safe, efficient and user-friendly farm tools and/or machineries and operator's workplace.

\section{DHM -important tool for virtual ergonomics}

Computer-aided technology enables many novel approaches in modeling, design and fabrication of farm tools and machines. CAD is mainly used for detailed engineering of 3D models and/or 2D drawings of physical components under a wide variety of representations. However, digital human representations in various forms are now being incorporated in computer-aided design of humanmachine systems for simulating man-machine interactions in virtual environment as real-world conditions. Digital Human Modeling (DHM) is special CAD software for developing 2D or 3D digital manikin (virtual human) from anthropometric and biomechanical databases for proactive ergonomic evaluation of product and workplace [10]. DHM software are now successfully being used in various sectors including military research [11,12], automobile sector [13,14], aerospace and aviation technology [15,16], industrial applications [17-19], health care and occupational safety [20-22], service industry [23,24] etc. DHM tools provide complete digital humans to explore infinite number of ergonomic scenarios including human size scaling, evaluation of posture, motion, reach, and vision within a computer-rendered environment [25-27,10]. Adoption of DHM looks very promising for improvement of agricultural tools, equipment as well as for off-road vehicle such as tractor and power tiller to make it more productive, efficient and comfortable to use. 


\section{Applications of DHM in agricultural sector}

Traditional human factors assessments for design and evaluation of workstations and vehicles involves manual measurements, user interfaces, and basic imagery or video recording to assess risks and identify possibility for improvement. Innovations in human factors and ergonomics assessments with computer-aided techniques, specifically the use of DHM, have proven to be very useful tools $[28,29]$. Using these tools, the visual scope and reach envelope of specific range of populations can be analyzed (e.g., EAI Jack) [25]. Furthermore, when integrated with virtual environments, DHM facilitates evaluation of workplace design, human reach, clearance and strength capability and safety analysis [30]. Physical mock-up is no longer necessary, and multiple aspects can be assessed with CAD which provides an efficient platform for digital mock-ups in virtual environments [3134].

Compared to other industries, DHM have been late coming into agriculture. Available literature suggests that steps have been initiated only in recent past by few researchers (Figure 1) such as Fathallah et al. (2009)[35] who investigated the abilities of varying anthropometric characteristics of youth operators to reach farm tractor controls by using SAMMIE CAD. Dooley (2012) [36] in his paper, discussed about physical and cognitive aspects of ergonomics in modern product development including agricultural vehicle. He inserted digital manikin in operator workplace (seat) and prescribed the relationship of pedals and steering wheel to floor and seat index point. Deisinger et al. (2000) [37] carried out a pilot project (with collaboration of John Deere Company in Mannheim, Germany) for analysis of reach envelope, visual field and force isodyne using ERGONAUT tool in a Virtual Environment (VE) for analysis of virtual and real data in a mixed mock-up. Computer models of digital human and the power carrier were developed by Wu et al. (2012) [38] using CAD software packages SolidWorks, I-DEAS and Jack to investigate the controllability of driving, driver's degree of comfort in driving, and the lumbar force condition of the operator while lifting cargo from cargo-bench of the carrier. Ying et al. (2010) [39] designed tractor cab and a combine harvester cab using OpenGL 3D computer graph software. The cabs were evaluated by a manikin of $50^{\text {th }}$ percentile for various hand and foot controls using virtual environment through the mixture of OpenGL and Multigen Vega Prime.

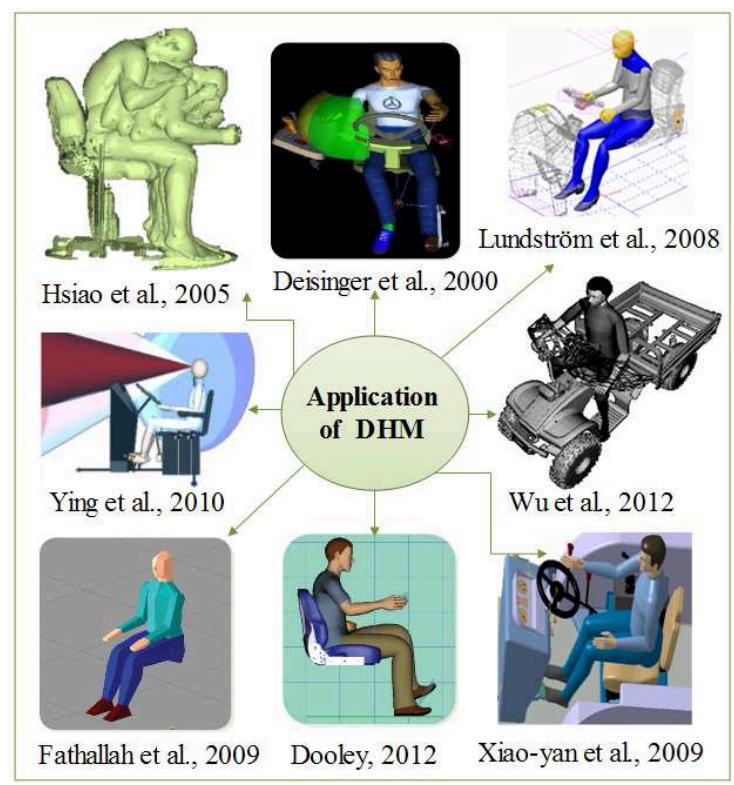

Figure 1. Application of DHMs for ergonomic evaluation of agricultural equipment/workplace

\section{Discussions and Conclusion}

Application of DHM is becoming increasingly popular today among designers and manufactures as it increases productivity, reduces design time-frame and decreases associated costs. Core functionality of DHM software is realistic display of anthropometric data and efficient analysis of 
ergonomic questions concerning sight, maximum force, reachability and comfort $[40,10,16]$. Designers can subsequently utilize a human model in the creation, modification, presentation and analysis [41] to ensure enough clearance and space to human for their ease and comfortable movement within workplace. From previous sections, it is very clear that DHM might have potential to contribute positively in agricultural sector. It is evident from tractor cab design and evaluation by various researchers $[42,43]$. There is no doubt about the fact that DHM is gradually gaining momentum in agricultural engineering setting such as tractor operator's workplace for operator cabs, adjustments for brake reach and linkages, seat position and seat height, visibility and for many more controls. Globally, most of the industries are steadily harnessing wide range of applications and benefits that DHM technologies offer, to replace and streamline traditional design systems and processes, increase efficiencies and productivity. However, application of these technologies to agriculture sector is still in its infancy. Although, farm equipment manufacturers are aware of the fact that traditional methods of designing and manufacturing are often costly, risky, high energy demanding, more time consuming, needing physical mock-ups and trial with real human subjects testing but in many instances they cannot afford initial investments or expenditure towards infrastructure development for modern technologies like DHM. There is an urgent need for creating general awareness about benefits offered by these technologies for their wide adoption. Awareness among researchers, scientists, engineers, designers and entrepreneurs could be achieved through organizing seminars, conferences, workshops etc. on this topic. Another hindrance for less adoption of DHM technologies is huge initial investments or expenditure towards infrastructure development and human resource training for these technologies. So, it is time to think how cost can be reduced to make it affordable for small scale manufactures. Integration of features of DHM software in general CAD software may reduce cost to some extent and would resolve many problems of file transfer from CAD to DHM software or vice versa. Moreover, further research is required for user friendly DHM software development and making manikins more realistic.

It is expected that present review on applications of DHM in agricultural sector would deliver a concrete knowledge base for those who are interested in agricultural engineering and ergonomics for farm machinery/tools design or agricultural workplace evaluation. Readers would be motivated to carry out further research in this line for transforming agricultural modernization from stagnation to growth.

\section{References}

[1] J. Helmkamp, W. Lundstrom, Tractor related deaths among West Virginia farmers. Ann. Epidemiol, vol. 12, no. 7 (2002), 510.

[2] A. Chowdhury, Sanjog J., S.M. Reddy, S. Karmakar. "Nanomaterials in the field of design ergonomics: present status." Ergonomics 55, no. 12 (2012): 1453-1462.

[3] M.G. Helander, 1999. Seven common reasons to not implement ergonomics. International Journal of Industrial Ergonomics, Vol. 25, No. 1 (1999), pp. 97-101.

[4] R.N. Sen, S. Sahu, Ergonomic evaluation of a multipurpose shovel-cum-hoe for manual material handling. International Journal of Industrial Ergonomics 17, no. 1 (1996): 53-58.

[5] H. Hsiao, J. Whitestone, B. Bradtmiller, R. Whisler, J. Zwiener, C. Lafferty, T.zy. Kau, M. Gross, Anthropometric criteria for the design of tractor cabs and protection frames. Ergonomics 48, no. 4 (2005): 323-353.

[6] S.P. Singh, L.P. Gite, N. Agarwal, Improved farm tools and equipment for women workers for increased productivity and reduced drudgery. Gender, Technology and Development 10, no. 2 (2006): 229-244.

[7] A. Ramahi, Fadi A. Fathallah, Ergonomic evaluation of manual weeding practice and development of an ergonomic solution. In Proceedings of the Human Factors and Ergonomics Society Annual Meeting, vol. 50, No. 13, pp. 1421-1425. SAGE Publications, 2006. 
[8] L. Vanderwal, R. Rautiainen, R. Kuye, C. Peek-Asa, T. Cook, M. Ramirez, K. Culp, K. Donham, Evaluation of long-and short-handled hand hoes for land preparation, developed in a participatory manner among women vegetable farmers in the Gambia. Applied Ergonomics 42, No. 5 (2011): 749-756.

[9] M.S. Khidiya, A Bhardwaj, An ergonomic approach to design hand tool for agricultural production. Work: A Journal of Prevention, Assessment and Rehabilitation 41 (2012): 13351341.

[10] J. Sanjog, S. Karmakar, H. Agarwal, C. Dattu Patil, Designing and Ergonomic Evaluation of a Shoe-Rack in CAD Environment. International Journal of Computer Applications, Vol. 49, No. 20 (2012): 38-41.

[11] A. Oudenhuijzen, G. Zehner, J. Hudson, H. Choi, On the Creation of 3D Libraries for F-16 Pilots in Their Crew Station: Method Development, Library Creation and Validation. Advances in Applied Digital Human Modeling, (2010): 9-18.

[12] S. Karmakar, D. Majumdar, M.S. Pal, D. Majumdar, Ergonomic study of ingress- egress of an army vehicle in simulated environment. In Proceedings of International Conference on Trends in Product Lifecycle, Modeling, Simulation and Synthesis (PLMSS), Bangalore, India, (2011): 69-74.

[13] R. Curran, G. Gomis, S. Castagne, J. Butterfield, T. Edgar, C. Higgins, C. McKeever, Integrated digital design for manufacture for reduced life cycle cost. International Journal of Production Economics 109, no. 1 (2007): 27-40.

[14] T. Dukic, M. Ronnang, M. Christmansson, 2007. Evaluation of ergonomics in a virtual manufacturing process. Journal of Engineering Design 18, no. 2 (2007): 125-137.

[15] R.F. Green, J. A. Hudson, A method for positioning digital human models in airplane passenger seats. Advances in Applied Digital Human Modeling, V.G. Duffy, ed., USA: Taylor \& Francis, pp. 1-8, 2010.

[16] S. Karmakar, D. Majumdar, M.S. Pal, D. Majumdar, Application of digital human modeling and simulation for vision analysis of pilots in a jet aircraft: a case study. Work: A Journal of Prevention, Assessment and Rehabilitation 41(2012): 3412-3418.

[17] A. Cimino, F. Longo, G. Mirabelli, A multimeasure-based methodology for the ergonomic effective design of manufacturing system workstations. International Journal of Industrial Ergonomics 39, no. 2 (2009): 447-455.

[18] J. Santos, Jose M. Sarriegi, Nicolás Serrano, Jose M. Torres, Using ergonomic software in non-repetitive manufacturing processes: A case study. International Journal of Industrial Ergonomics 37, no. 3 (2007): 267-275.

[19] M.L.L.R. Okimoto, Digital human modeling in product evaluation. In: W. Karwowski, M.M. Soares, and N.A. Stanton, eds. Human Factors and Ergonomics in Consumer Product Design, New York: Taylor \& Francis, (2011): 325-331.

[20] L. Hanson, D. Högberg, D. Lundström, M. Wårell, Application of human modelling in health care industry. In Digital Human Modeling, Springer Berlin Heidelberg, (2009), 521-530.

[21] M. Kouchi, M. Mochimaru, Simulation of the body shape after weight change for health-care services. In AHFE 2010: Proceedings of the 3rd International Conference on Applied Human Factors and Ergonomics, (2010): 40-44..

[22] A. Mohammadi, A Study of the dynamic model in the analysis of whole body vibration in manufacturing environments. Advances in Applied Digital Human Modeling, V.G, Duffy, ed., USA: Taylor \& Francis, (2010): 359-368.

[23] Y. Motomura, Large-Scale data based modeling in everyday life for service engineering. Advances in Applied Digital Human Modeling, V.G, Duffy, ed., USA: Taylor \& Francis, 2010, pp. 576-586.

[24] K. Case, R. Marshall, D. Hogberg, S.Summerskill, D.Gyi, and R. Sims, HADRIAN: Fitting trials by digital human modelling. In: Digital Human Modeling, pp. 673-680.Springer Berlin Heidelberg, (2009). 
[25] D.B. Chaffin, D. Thompson, C. Nelson, J.D. Ianni, P.A. Punte, D. Bowman, Digital human modeling for vehicle and workplace design.Warrendale, PA: Society of Automotive Engineers, (2001).

[26] J. Faraway, M.P. Reed, 2007. Statistics for digital human motion modeling in ergonomics. Technometrics, 49, no 3 (2007): 277-290.

[27] H. Bubb, F. Engstler, F. Fritzsche, C. Mergl, O. Sabbah, P. Schaefer, I. Zacher, The development of RAMSIS in past and future as an example for the cooperation between industry and university. International Journal of Human Factors Modelling and Simulation 1, no. 1 (2006): 140-157.

[28] U. Jasnoch, B. Anderson, M. Koch, J. Rix, Beyond digital mock-ups: Human aspects in new products. In Proceedings of the Autofact, (1997).

[29] J. Rix, A. Heidger, C. Helmstädter, R. Quester, T. Ringhof, Integration of the Virtual Human in the CA Design Review. Landau, K.: Man-Machine Interfaces (1999).

[30] A.Stephens, M.L.H. Jones, Workplace methods and use of digital human models. Handbook of Digital Human Modeling, USA: Taylor and Francis, 6 (2009), 1-6.

[31] J.M. Porter, C.S. Porter, Turning automotive design 'inside-out', International journal of vehicle design 19, no. 4 (1998).

[32] J.M. Porter, M.T. Freer, K. Case, Computer aided ergonomics. Engineering Designer, Vol. 25, No. 2, (1999): 4-9.

[33] J. Yang, J.H. Kim, K. Abdel-Malek, T. Marler, S. Beck, G.R. Kopp, A new digital human environment and assessment of vehicle interior design. Computer-Aided Design 39, no. 7 (2007): 548-558.

[34] T.M. Cappelli, V.G. Duffy, Motion Capture for Job Risk Classifications Incorporating Dynamic Aspects of Work. Digital Human Modeling for Design and Engineering Conference, Lyon, 4-6 July 2006. Warrendale: SAE International.

[35] F.A. Fathallah, J. H. Chang, W. Pickett, B. Marlenga, Ability of youth operators to reach farm tractor controls. Ergonomics 52, no. 6 (2009): 685-694.

[36] W.K. Dooley, Ergonomics and the development of agricultural vehicles. American Society of Agricultural and Biological Engineers (ASABE) distinguished lecture Series No. 36, USA, (2012).

[37] J. Deisinger, R. Breining, A. Robler, I. Holfe, D. Ruckert, Immersive ergonomic analyses of console elements in a tractor cabin. In Proceedings Fourth Immersive Projection Technologies Workshop, Iowa, (2000).

[38] G.J. Wu, J.J. Lin, Y.C. Chiu, Computer aided human factor engineering analysis of a versatile agricultural power. Proceedings of the 6th International Symposium on Machinery and Mechatronics for Agriculture and Biosystems Engineering (ISMAB) 18-20 June, Jeonju, Korea, (2012).

[39] Q. Ying, L. Hui, S. Zhenghe, Z. Zhongxiang, M. Enrong. Design of agricultural equipment cab based on virtual reality. International Conference on Advanced Technology of Design and Manufacture (ATDM), IET, (2010), 62-67.

[40] A. Naumann, M. Rotting, Digital human modeling for design and evaluation of humanmachine systems. MMI-Interaktiv, 12 (2007), 27.

[41] L. Hanson, M. Blomé, T. Dukic, D. Högberg, Guide and documentation system to support digital human modeling applications. International Journal of Industrial Ergonomics 36, no. 1 (2006): 17-24.

[42] D. Lundström, T. Nevaranta, L. Hanson, D. Högberg, A. Sundin, Visualization of comfort and reach in cab environment. 40th Annual Conference of the Nordic Ergonomics Society, Reykjavik, Iceland, August 11-13, (2008).

[43] Y. Xiao-yan, S. Zheng-he, Z. Zhong-xiang, and M. En-rong, Expert System for Tractor Cab Man-Machine Interface Evaluation. In Computational Intelligence and Software Engineering, 2009.CiSE 2009. International Conference on, pp. 1-4. IEEE, (2009). 